\title{
Recurrent laryngeal nerve injury associated with Air-Q
}

\author{
M Bhardwaj ${ }^{*}$, K Kaur ${ }^{2}$, R Saxena ${ }^{3}, S$ Taxak $^{4}$ \\ Assistant Professor ${ }^{1 *}$, Associate Professor ${ }^{2}$, Senior Resident ${ }^{3}$, Senior Professor ${ }^{4}$, Department of \\ Anaesthesia, Pt. B.D Sharma University of Health sciences, Rohtak, India.
}

\begin{abstract}
We report a case of 55-year-old patient who presented for internal fixation of fractured shaft of humerus, tibia and fibula on the right side. Airway was secured with air- Q size 3.5 at the first attempt. Cuff was inflated with $15 \mathrm{ml}$ air in accordance with the manufacturer's labelled recommendation. After removal, he started feeling discomfort due to inability to speak. Indirect laryngoscopy revealed left vocal cord palsy and decreased movement of left arytenoid. Patient recovered completely in 8 weeks.
\end{abstract}

Keywords: Recurrent laryngeal nerve injury; air-Q ILA

\section{Introduction}

The Air-Q Intubating Laryngeal Airway (ILA) is a supra-glottic airway used as a primary airway and as an aid for intubation in situations of anticipated or unanticipated difficult airway. We encountered a case of recurrent laryngeal nerve injury following use of air-Q ILA. Our literature search did not reveal any clinical report of vocal cord paralysis caused by air-Q.

\section{Case Report}

A 55yr old male, ASA status I, was posted for internal fixation of fracture proximal humerus and tibia and fibula on the right side. Airway examination revealed a Mallampati class III score. In the operating theatre following routine monitoring, general anaesthesia was administered. Airway was secured with air-Q size 3.5 after lubricating with a water-based gel in first attempt. Cuff was inflated with $15 \mathrm{ml}$ air as per manufacturer's recommendation.

Pressure manometer-guided cuff inflation was not used as the manufacturer makes no

*Correspondence: M Bhardwaj

E mail: drbmamta@gmail.com

0000-0002-3942-3268

Received: 03/03/2017

Accepted: $27 / 05 / 2017$

DOI: 10.4038 /slja.v25i2.8219

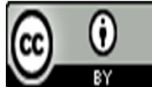

recommendation for cuff inflation pressure, but only a maximum cuff inflation volume. ${ }^{1}$ Head was placed on a head ring in neutral position. Anaesthesia was maintained with isoflurane, $\mathrm{N}_{2} \mathrm{O}$ and oxygen. Patient was ventilated with a tidal volume of $500 \mathrm{ml}$ and respiratory rate of 12 per minute and peak airway pressure of

$14 \mathrm{cmH}_{2} \mathrm{O}$. Surgery lasted for three hours and $45 \mathrm{mins}$. At the end of surgery air-Q was removed gently. There was no visible blood on the surface of the cuff at removal. But immediately after removal, patient started feeling discomfort due to speech difficulty. Intravenous hydrocortisone $100 \mathrm{mg}$ and dexamethasone $8 \mathrm{mg}$ were administered. After 6 hours of continuous observation slight improvement in voice was observed, but was still hoarse with poor cough reflex. Indirect laryngoscopy (IDL) could not be performed as the patient was not able to sit due to pain. On subsequent follow-up there was a gradual improvement in pitch of voice day by day. After 7 days, IDL revealed left vocal cord palsy, decreased movement of left arytenoid, while right vocal cord was mobile with adequate glottic opening. Eight weeks postoperatively hoarseness resolved completely with normal vocal cords movement on IDL.

\section{Discussion}

Probable cause for nerve injuries associated with LMA is either pressure neuropraxia from 
the tube (lingual) or cuff (hypoglossal and RLN). Other causes are stretch neuropraxia from head/neck/body positional changes, chemical neuritis by use of wrong lubricant and local inflammation from insertion trauma, too small LMA, use of $\mathrm{N}_{2} \mathrm{O}$, overinflated cuff, inexperience, difficult insertion and alternative insertion techniques. ${ }^{2}$ Diffusion of $\mathrm{N}_{2} \mathrm{O}$ into the cuff might increase intracuff volume by up to $38 \%$ in 30 minutes. $^{3}$ True mechanism remains unclear, which makes effective prevention and treatment of this disorder difficult.

Zhang $\mathrm{J}$ hypothesized that demyelinating neuropraxia resulting from direct mechanical compression contributes to RLN injury associated with LMA. A series of clinical cases which showed that RLN palsy may occur as a result of cuff over-inflation and/or prolonged LMA insertion period support the hypothesis. ${ }^{4}$ Vocal changes experienced by patients' shortly after RLN palsy are common, transient, and usually not significant. RLNP is known to have a favourable prognosis with reported recovery of vocal cord mobility in $68.4 \%$ of patients. ${ }^{5}$

The air-Q ILA is a $\mathrm{C}$ pre-shaped laryngeal airway with a rapid learning curve and is easy to use. It is made up of medical grade silicon and is latex free. Silicone is more permeable to $\mathrm{N}_{2} \mathrm{O}$ than PVC. Data on use of air-Q is currently limited. Work by Galgon et al showed that more patients who received the air-Q reported sore throat and pain on swallowing as compared with those receiving the ProSeal and gross blood was noted on the cuff more in cases with air Q. The study concluded that the air-Q performs well as a primary airway during the maintenance of general anaesthesia but with a higher incidence of postoperative oropharyngolaryngeal complaints. ${ }^{1}$

Factors that may have contributed to the injury in our patient are upper arm surgery with lot of traction, head firmly taped to the table, use of
$\mathrm{N}_{2} \mathrm{O}$, prolonged procedure and unmonitored cuff pressure.

We conclude that submaximal cuff inflation should be used as pressure neuropraxia seems to be the most likely explanation for this case of left RLN palsy. Preventive measures include single smooth insertion, using appropriate size, time to time measurement of intracuff pressure, and early diagnosis and management of malposition. Despite the low incidence of nerve injuries associated with use of LMA, vigilant adherence to evidence based medicine techniques and recommendations of manufacturer's manual can help prevent such complications.

\section{References}

1. Galgon RE, Schroeder KM, Han S, Andrei A, Joffe A M. The air-Q intubating laryngeal airway vs the LMA-ProSeal $^{\mathrm{TM}}$ : a prospective, randomised trial of airway seal pressure. Anaesthesia 2011; 66: 10931100. https://doi.org/10.1111/j.1365-2044.2011.06863.x PMid:21880031 PMCid:PMC3358348

2. Brimacombe J, Clarke G, Keller C. Lingual nerve injury associated with the ProSeal laryngeal mask airway: a case report and review of the literature. British journal of anaesthesia 2005;95:420-3. https://doi.org/10.1093/bja/aei187 PMid:16006489

3. Lumb AB, Wrigley MW. The effect of nitrous oxide laryngeal mask cuff pressure. Anaesthesia 1992;47:320-3.

https://doi.org/10.1111/j.13652044.1992.tb02173.x

PMid:1519684

4. Zhang J, Zhao Z, Chen Y, Zhang X. New insights into the mechanism of injury to the recurrent laryngeal nerve associated with the laryngeal mask airway. Med Sic Monit. 2010;16(5)HY 7-9

5. Yumoto E, Minoda R, Hyodo M, Yamagata T. Causes of recurrent laryngeal nerve paralysis. AurisNasus Larynx. 2002;29:41-5. 